\title{
Performance of Urban Corridor Using Speed Profile Data of Automobile
}

\author{
T. Vijay Kumar ${ }^{1 *}$, Drisya Manghat ${ }^{2}$, L. Geetha ${ }^{3}$, Vivek R. Das ${ }^{4}$ \\ ${ }^{l} P G$ Student, Department of Construction Technology and Management, Dayananda Sagar College of \\ Engineering, Bangalore, India \\ ${ }^{2}$ Research Scholar, Department of Civil Engineering, National Institute of Technology, Calicut, India \\ ${ }^{3}$ Assistant Professor, Department of Construction Technology and Management, Dayananda Sagar College of \\ Engineering, Bangalore, India \\ ${ }^{4}$ Professor, Department of Construction Technology and Management, Dayananda Sagar College of \\ Engineering, Bangalore, India \\ *Corresponding author: 3092vijaykumar@gmail.com
}

\begin{abstract}
The level of service on urban roads quality experienced by the drivers will be varying it is difficult to study the variations due to heterogeneous traffic flow conditions of Indian urban roads. As per TRB, 2010 macroscopic traffic flow parameters are found to be deficient in capturing the quality of service on urban roads experienced by users. Hence the objective of the study is to develop new methodology to evaluate the urban roads in heterogeneous traffic conditions considering the microscopic parameters of traffic flow in a four-lane divided urban corridor. The speed profile of the motorised two-wheelers both in free flow and peak flow were collected from the urban corridor of Bangalore Karnataka, India. Using GPS based mobile application. From the speed profile data, the speed variation characteristics were studied. The various speed indices considered in the study are VN (Velocity noise), CV (Co-efficient of variation), AN (Acceleration noise), and MVG (Mean Velocity Gradient). The $\mathrm{CV}$ is considered as the measure of effectiveness, higher the $\mathrm{CV}$ more will be the variation of quality experienced by the road users.
\end{abstract}

Keywords: Co-efficient of variation (CV), Level of service, Urban corridor.

\section{Introduction}

The fast advancement of urbanizing and the upturn of megacities including crowded lots of occupant matters formidable threat to the developing countries with heterogeneous traffic conditions like India, preservation along the universal trends monetary expansion have escort India looking towards incredible urbanization over the past centenary. Indian urban areas currently that covers a broad range of megacities, downtowns, metropolis of not all that likely in provision of connection between main cities and intercity transportation. Transportation in this situation has been a casualty of disregard, disrespect, and distraction everything at these by one time. Survey conducted in as on March 31, 2016. 230 million registered vehicles were plying on the Indian roads (The Ministry of Road Transport \& Highways, Government of India) the annual rate of growth of motor vehicle $9.9 \%$ between the 2006 and 2016 decade. Bengaluru had 55.59 lakh vehicles as on March 31, 2015, as against the 88.27 lakh vehicles in New Delhi. Bengaluru is followed by Chennai, which has 44 lakhs (Ministry of statistics and program Implementation, 2015). Primary complication is not about the total count of automobiles in the country nonetheless the large quantity over some elected metropolises, especially in urban metropolises (million-plus) this is frightening to notice that $32 \%$ of these numbers of automobiles were playing alone in the urban cities that establish around $11 \%$ of the total population as per the MORTH 2003.

India represents a developing country with different variety of cutler diversity and habits. Our traffic condition specifically on urban streets is more likely to have extremely heterogeneous traffic conditions dwelling of varied kinds of different vehicles consisting of distinctive operational styles. No suitable methods are present in current scenario that can be applicable for determining the level of service (LOS) which consists of heterogeneous traffic conditions like Indian urban corridors conditions. Determination of level of service of an urban corridor is undoubtedly essential has this becomes initial stage of defining level of service as per the traditional practices. The level of service is influenced by the parameters like planning, design, and operational conditions within the highway projects and also the allotment of restricted monetary required assets among ongoing highway projects at the required correct time. So urban corridor need to be defined with proper methodology for Indian context in determining the level of service criteria.

\section{A. The statement of the problem}

Urban streets are not going through the afflicted development of urbanization within developing countries which result in control position on road accessible for driver reducing every day. The urban corridor connections in recent days were awkwardly difficult due to problem like reducing speeds, heightened congestion, heightened travel time, reduced in level 
of service, and heightened misadventure percentage. High consistently growing interest of an urban corridors and a diversity of issues that appear day-by-day has transcended capability of conventional practices of traffic practices. New road construction and huge roads is not the solution to fix the current transportation problems due to the presence of a stumbling block in environmental and financial matters such that the accessible urban transportation networks has to be employ more precisely to achieve an appropriate management system for traffic flow in urban corridors which requires an immense sum of travel time, travel speed, and delay data.

The fundamental characteristics of Indian traffic conditions different from those which have developed economies named as developed countries and even the driving behavior is also hugely distinctive from even the progressive economies like China, Taiwan, Malaysia, and Indonesia (Indo-HCM 2017). From the studies we come to know that Highway capacity manual (HCM) is in US standards, it will not match to Indian conditions adequately.

\section{B. Objectives}

The main aim in this research objective is to obtain exact reasonable traffic condition factor influencing in heterogeneous traffic condition for travel quality on specified facility experienced by automobile user.

- Collecting Free flow, Peak flow speed data in the study corridor using GPS based mobile application.

- Plot the graph of speed profile both for Free flow, Peak flow and compare, identify the variation in speed profile.

- Calculations are done to obtain the Speed indices characteristics such as VN, CV, AN, and MVG as to calculate for urban corridor which they are considered as measure of validity.

\section{Urban Streets and Level of Service}

\section{A. Urban streets}

Progressive system of road network facility consist urban corridors positioned in between neighborhood roads, multilane urban and rural highway. The distinction between them is by resolved chiefly by a road capacity, control condition, geometric qualities, and surrounding road improvement. The arterial street is streets that essentially serve longer through outings. Nonetheless, giving admittance to adjoining business and private land utilizes is additionally a significant capacity of urban streets. Urban streets provide commercial activity and transport flow inside private, business, and modern zones. Their entrance work is a higher priority than that of arterials and dissimilar to arterials, their activity isn't constantly overwhelmed by traffic signals. Streets with downtown are signalized facilities regularly take after urban arterial. It travels through traffic as well as give admittance to nearby organizations to transit transports, passenger cars and heavy vehicles. Road side developments in the intersections of downtown which are frequently more noteworthy than $20 \%$ for all volume of traffic since inflow downtowns commonly includes a considerable measure of circulatory traffic within it. Public clashes with a path impediment made through halting taxis, transports, heavy vehicles and parked automobiles implement for choppiness in flow for traffic that are commonplace of city streets. The city streets capacity can be change with a time in a few selected downtown roads, changed over to a kind of arterial activity in a peak flow tasks. The three main principle factors that affect the speed in the urban street are; condition of street, communication within the traffic and vehicles permits. This component additionally influences the nature of administration for the urban streets.

\section{1) Segmenting the urban street}

The level of service analysis and the capacity operation aspects were performed on a segment of the urban corridor. It is a one-directional road between two sequential signalised convergences. Toward the beginning of the examination, the area and length of the metropolitan road to be viewed as must be characterized. All pertinent to physical qualities, mathematical details, signal, and traffic information ought to be distinguished. Thought ought to be given to all degree of the metropolitan road for the most part at any rate $1.5 \mathrm{~km}$ is essential for urban regions and for different regions with 3.0 $\mathrm{km}$.
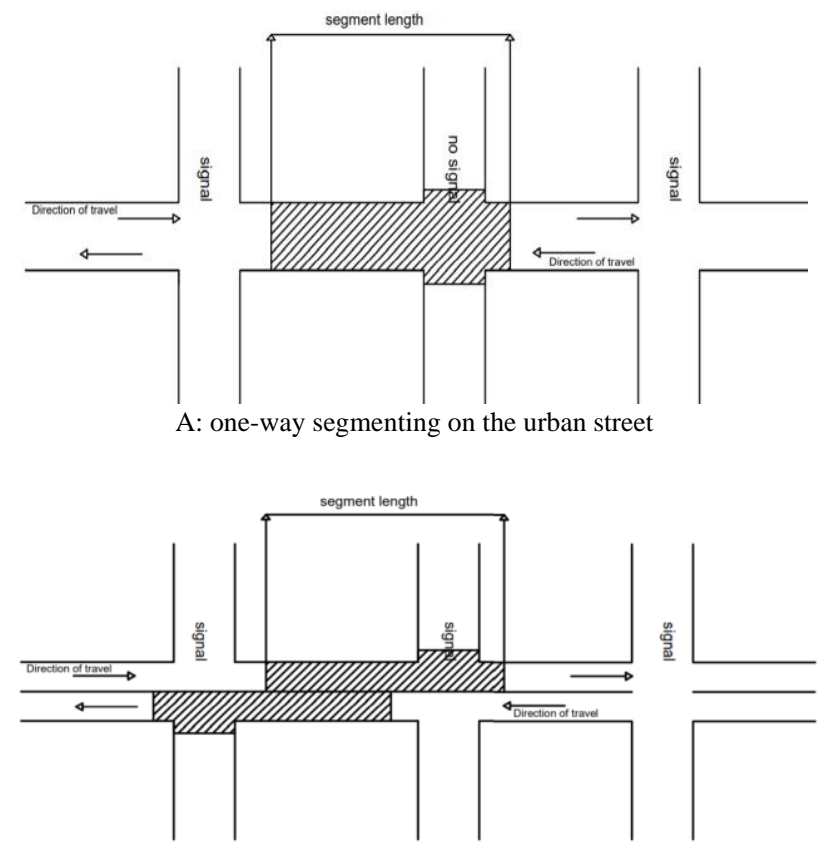

B: two-way segmenting on the urban street

Fig. 1. Segmenting urban street in different ways for Indian condition

\section{B. Level of service}

The level of service (LOS) of an urban street depends on travel speed along the segment considering only through movements or for the whole corridor (including many segments) viable. Urban streets include travel speed as one of the essential service measure. The travel speed is averaged by 
computing the running time on the street with the delay caused in the controlled developments in the signalised intersections. The urban street level of service is effected both control delays caused due to signalised intersection and also the number of signals present for each kilometer. Improper sign planning, helpless movement, and expanding traffic stream can corrupt the LOS quality considerably. Urban streets having moderate to higher signal density (i.e., consist of higher than one signal for each kilometer) vulnerable to these variables, and very low quality LOS may can watched earlier than any noteworthy issues happen. Then again, longer urban street segments including intensely stacked intersection may be servicing at a less LOS quality. Every vehicles going straightforwardly through an urban street segment without not turning on a lane is known as through movement of the vehicle.

\section{Factors influencing the level of service for urban road}

Conventional style for assessing urban streets level of service relied upon a medium-sized vehicle mean speed and also its volume to capacity ratio. Vehicles have broadly differing operational attributes in the heterogeneous traffic flow in the urban streets. The ALOS experience by the diverse automobile user contrasts altogether differently, because of vacillations in their physical and utilitarian attributes for comparable traffic stream. Utilizing the total proportion of the equivalent ALOS basis esteems for various automobile users against the genuine scenario (Drisya and Aswathy 2017; Drisya and Krishanmurthy 2017). Consequently, the level of service measures of a various methodologies should be created dependent on the traffic stream boundaries watched ceaselessly on the minuscule stage. Travel speed attributes of flow boundaries were influenced and they are discussed in the following sections.

\section{1) Speed indices}

It is a flighty boundaries performed to indicate variation in speed qualities for a travel, that are precisely portray behavior of users observation for a heterogeneous rush in peak hour gridlock situation. Different speed indices considered for this examination are velocity noise (VN), the coefficient of variation of speed (CV), acceleration noise (AN) and, the mean velocity gradient (MVG) of the speed. These indices are clarified in detail underneath.

VN (velocity noise) is the standard deviation of speed along the street. This portrays the variation in speed for vehicle over the separation or movement span, and in a roundabout way mirrors the degree of exertion expected to put by a client for support the speed profile. Consequently, this is reasonable quality measure to evaluate quality of level of service experienced by the individual driver. It is numerical articulation represented in equation (1).

$$
\mathrm{VN}=\sqrt{\frac{\sum_{i=1}^{N}\left(V_{i}-M S\right)^{2}}{N-1}}
$$

Where, $v_{i}$ is the instantaneous speed of the vehicle @ the $\mathrm{i}^{\mathrm{th}}$ the interval of the time or distance in $\mathrm{km} / \mathrm{hr}$.

$\mathrm{N}$ is the total number of time intervals during the trip and,

$\mathrm{M}$ is the mean speed of the given trip in $\mathrm{km} / \mathrm{hr}$.

$\mathrm{CV}$ is inferred measurement gotten by proportion the standard deviation of speed to mean speed. It is numerical articulation represented in equation (2).

$$
\mathrm{CV}=\frac{\mathrm{VN}}{\mathrm{MS}} \mathrm{X} 100 \ldots \ldots \ldots
$$

Acceleration Noise is characterized as the standard deviation of acceleration along the street. It is determined by utilizing equation (3),

$$
\mathrm{AN}=\sqrt{\frac{\sum_{i=1}^{N}\left(A_{i}-M A\right)^{2}}{N-2}}
$$

Where, $A_{i}$ is the difference in speed of the vehicle between the $\mathrm{i}^{\text {th }}$ interval to $(i+1)^{\text {th }}$ interval and, MA is the mean acceleration of the vehicle.

Mean Velocity Gradient is characterized as the proportion of the acceleration noise to the mean speed and count by utilizing the equation (4).

$$
\mathrm{MVG}=\frac{\mathrm{MA}}{\mathrm{MS}} \mathrm{X} 100 \ldots \ldots
$$

\section{Methodology}

In this methodology adds to the system for the assessment of urban corridors. The field information on the travel speed and travel time is accessible, gather through the GPS based portable application; this structure can be utilized to decide the metropolitan road's level of service. The unconventional parameters which influence the quality of traffic were identified. Fig. 2 illustrates the framework of methodology for evaluating the quality of LOS on an urban corridor.

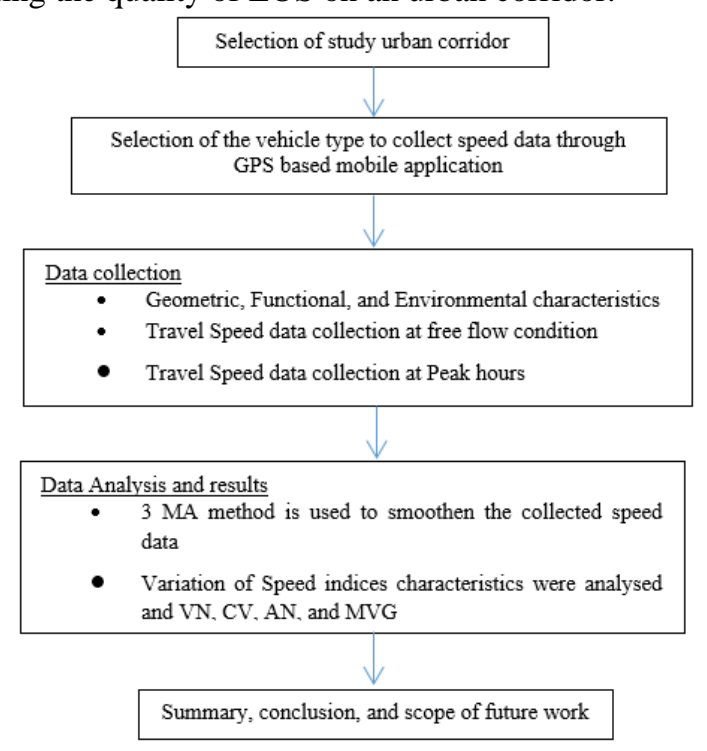

Fig. 2. Framework of methodology for evaluating the quality of LOS in the urban corridor 
Volume-3, Issue-10, October-2020

\section{IJRESM journals.resaim.com/ijresm | ISSN (Online): 2581-5792 | RESAIM Publishing}

\section{Study Stretches and Data Collection}

\section{A. Introduction}

The data collected from the selected study stretches which are from Bangalore south zone in Bangalore urban district, Karnataka, India. The study stretches having four-lane two-way divided urban corridors having length of $2.95 \mathrm{~km}$ with signalised intersections. The corridor from the Kasturba colony to 7th block Banashankari as represented in the map shown in Fig. 3 has a distance of $2.95 \mathrm{~km}$ with eight segments with a signalised intersection. Segment 1 which as a distance of $190 \mathrm{~m}$ with a four-arm signalised intersection as shown in Fig. 4.a, having average road width $12.1 \mathrm{~m}$ over the entire segment, there is no parking facility on side of the road, there are three approach road to the segment, one bus stop location and the distance from the intersection is $50 \mathrm{~m}$.

Segment 2 as a distance of $1750 \mathrm{~m}$ with a three-arm signalised intersection as shown in Fig. 4.b, having average road width $11.3 \mathrm{~m}$ over the entire segment, there is a parking facility of $460 \mathrm{~m}$ on side of the road, it consists of eight approach road to the segment with three bus stop location and the distance from the intersection is $200 \mathrm{~m}$.

Segment 3 as a distance of $450 \mathrm{~m}$ with a four-arm signalised intersection as shown in Fig. 4.c, having average road width of $11.1 \mathrm{~m}$ over the entire segment, there is no parking facility on side of the road, it includes a two-approach road with one bus stop location on the segment and the distance from the intersection is $150 \mathrm{~m}$.

Segment 4 as a distance of $560 \mathrm{~m}$ with a four-arm signalised intersection as shown in Fig. 4.d, having average road width of $10.8 \mathrm{~m}$ over the entire segment, there is no parking facility on side of the road, it includes a five-approach road with two bus stop location on the segment and the distance from the intersection is $350 \mathrm{~m}$.

Segment 5 as a distance of $250 \mathrm{~m}$ with a four-arm signalised intersection as shown in Fig. 4.d, having average road width of $11.2 \mathrm{~m}$ over the entire segment, there is no parking facility on side of the road, it includes a two-approach road with one bus stop location on the segment and the distance from the intersection is $50 \mathrm{~m}$.

Segment 6 as a distance of $420 \mathrm{~m}$ with a four-arm signalised intersection as shown in Fig. 4.c, having average road width of $11.3 \mathrm{~m}$ over the entire segment, there is no parking facility on side of the road, it includes a three-approach road with two bus stop location on the segment and the distance from the intersection is $100 \mathrm{~m}$.

Segment 7 as a distance of $570 \mathrm{~m}$ with a three-arm signalised intersection as shown in Fig. 4.b, having average road width $11.1 \mathrm{~m}$ over the entire segment, there is a no parking facility of on side of the road, it consists of six approach road to the segment with two bus stop location and the distance from the intersection is $200 \mathrm{~m}$.

Segment 8 which as a distance of $1710 \mathrm{~m}$ with a four-arm signalised intersection as shown in Fig. 4.a, having average road width $11.6 \mathrm{~m}$ over the entire segment, there is $300 \mathrm{~m}$ parking facility on side of the road, there are seven approach road to the segment, two bus stop location and the distance from the intersection is $250 \mathrm{~m}$.

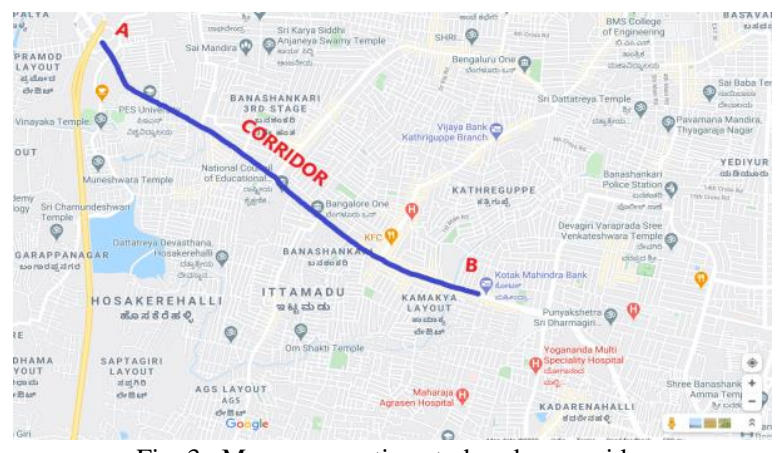

Fig. 3. Map representing study urban corridor

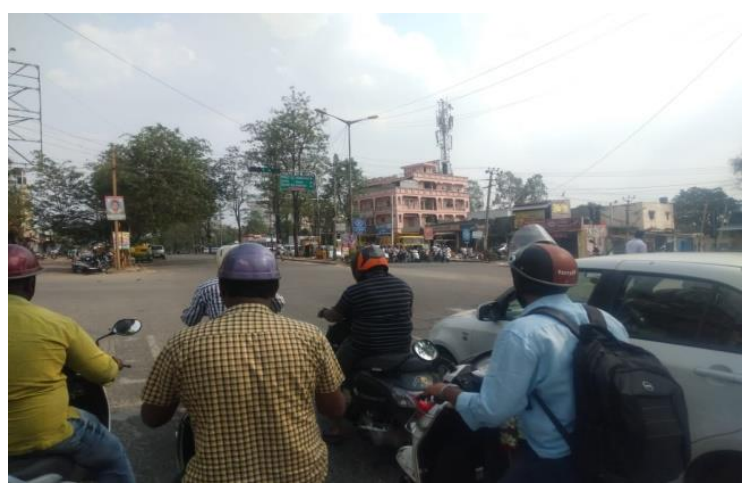

Fig. 4(a) Segment $1 \&$ Segment 8, four-arm signalised intersection

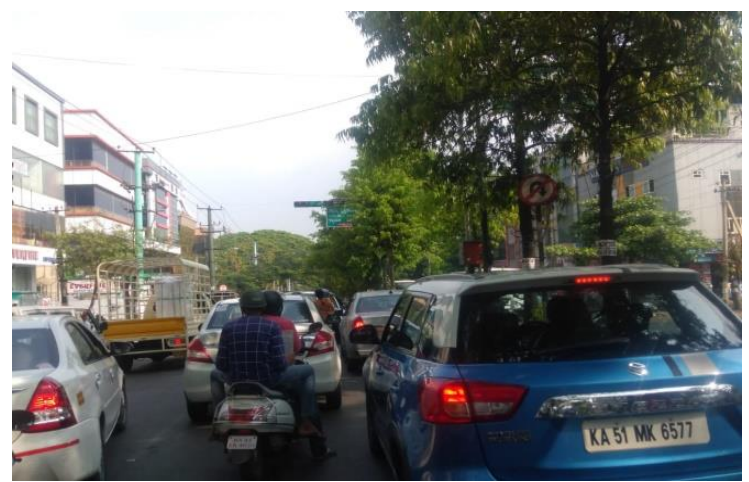

Fig. 4(b) Segment 2 \& Segment 7, three-arm signalised intersection

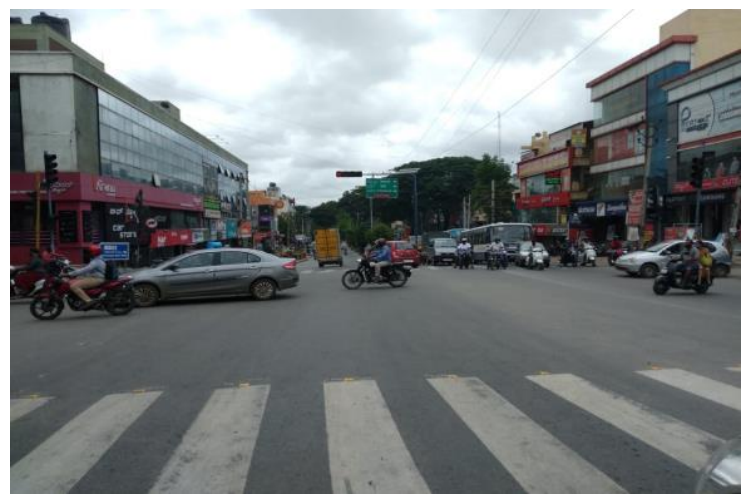

Fig. 4(c) Segment 3 \& Segment 6, four-arm signalised intersection 


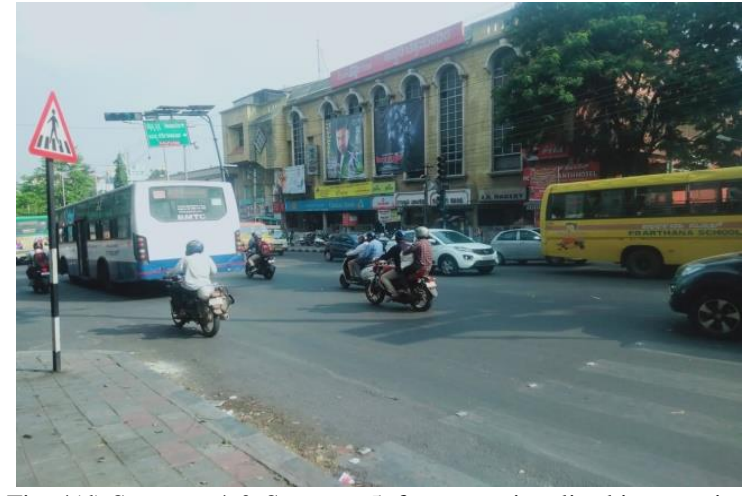

Fig. 4(d) Segment $4 \&$ Segment 5, four-arm signalised intersection

\section{B. Data collection}

The map indicating the study corridor is given in Fig. 3. The two sorts of data were collected to understanding the quality of travel over study corridors. Essentially the road inventory data was gathered from isolating the study corridors into segments. This was gotten partly measured from the site and partly from records. Due to variations in corridors geometric characteristics were different alongside the length. The segmental evaluation analysis was done for every corridor. Segment is defined as a combination of midblock and its first intersection. The next, second kind of data gathered was the mean speed of peak flow and free flow of the automobile in the study corridors. The GPSbased mobile application was used to collect the speed data of automobile. It records the speed of automobile second-bysecond. In this GPS application alongside the speed and time data, it also records the location coordinates to decide parameters of the traffic, the traffic parameters like travel speed and travel time variation characteristics (instantaneous and average). The itemized segments characteristics are given in Table 1.

The peak flow speed data were collected from 8:30AM to 11:30AM and 2:30PM to6:00 PM with the motorised twowheelers (MTW) with one trip every 15 minutes in corridor. The free flow speed data were collected separately during the early morning from 4:00AM to 6:00AM when the traffic flow was significantly less. 12 trips were made to collect the frequent changes in the traffic characteristics of the study corridor using a motorized two-wheeler with one person riding (more than 10year riding experience) the vehicle and, another person operating the mobile application.

\section{Road conditions depicting the quality of LOS in study urban corridor}

In the corridor the condition of road is improper in some segments, it consist of more number of shallow and deep potholes, in some portion of segments the top pavement layer has been drained off they are shown in Fig. 5.
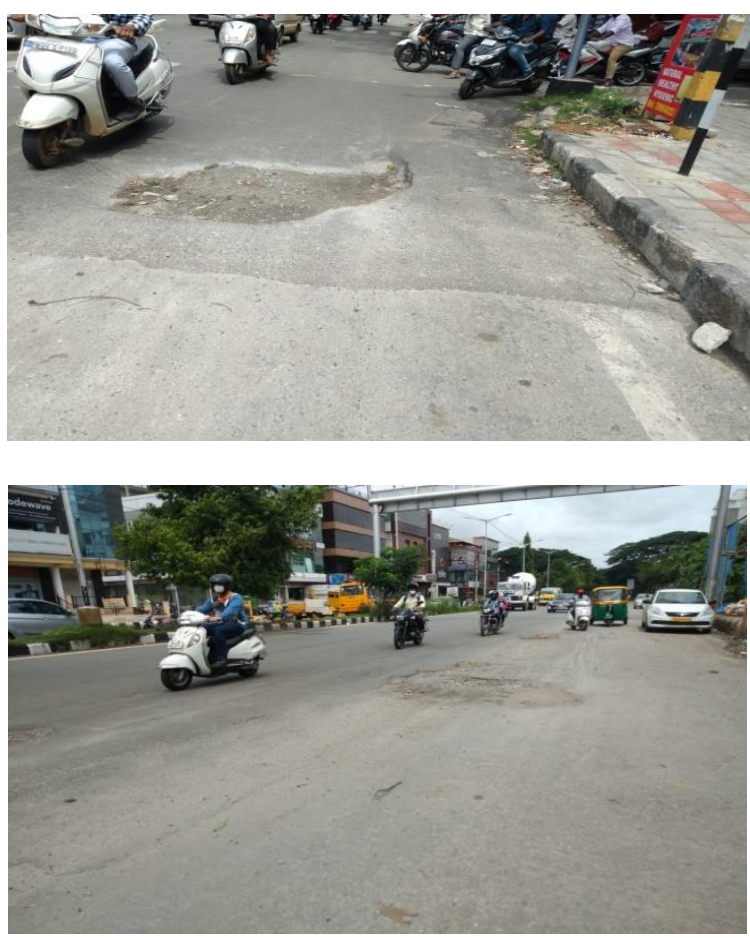

Table 1

The study corridors segments characteristics

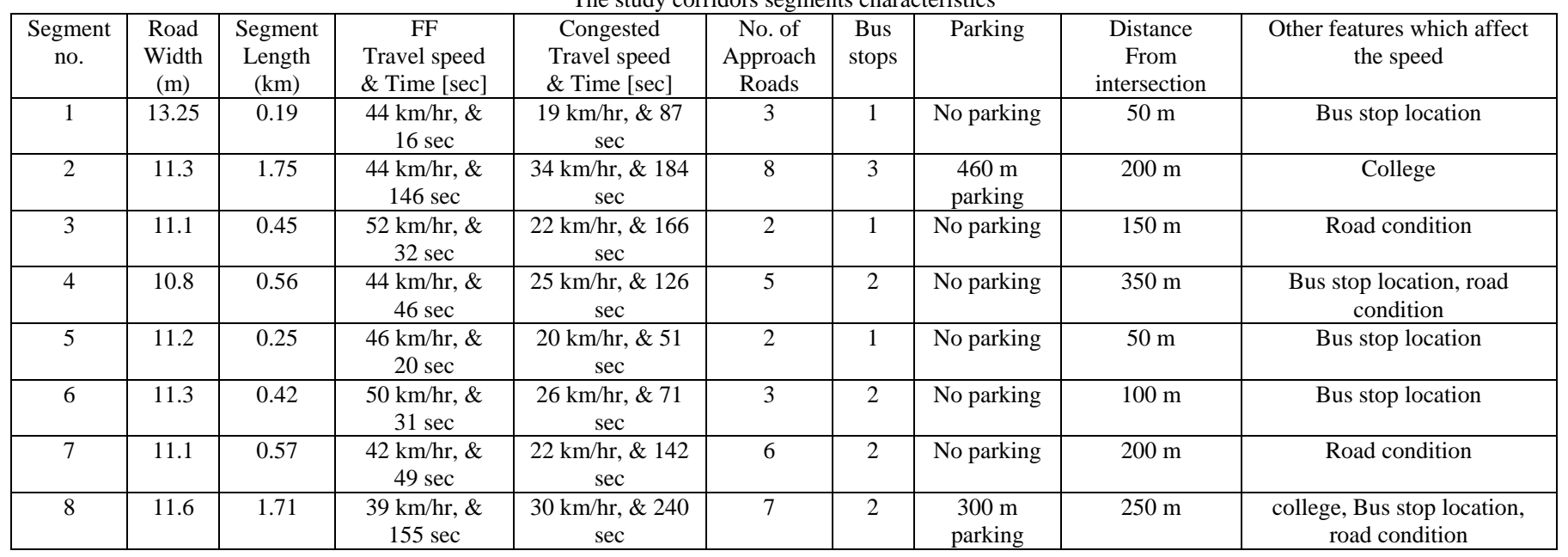



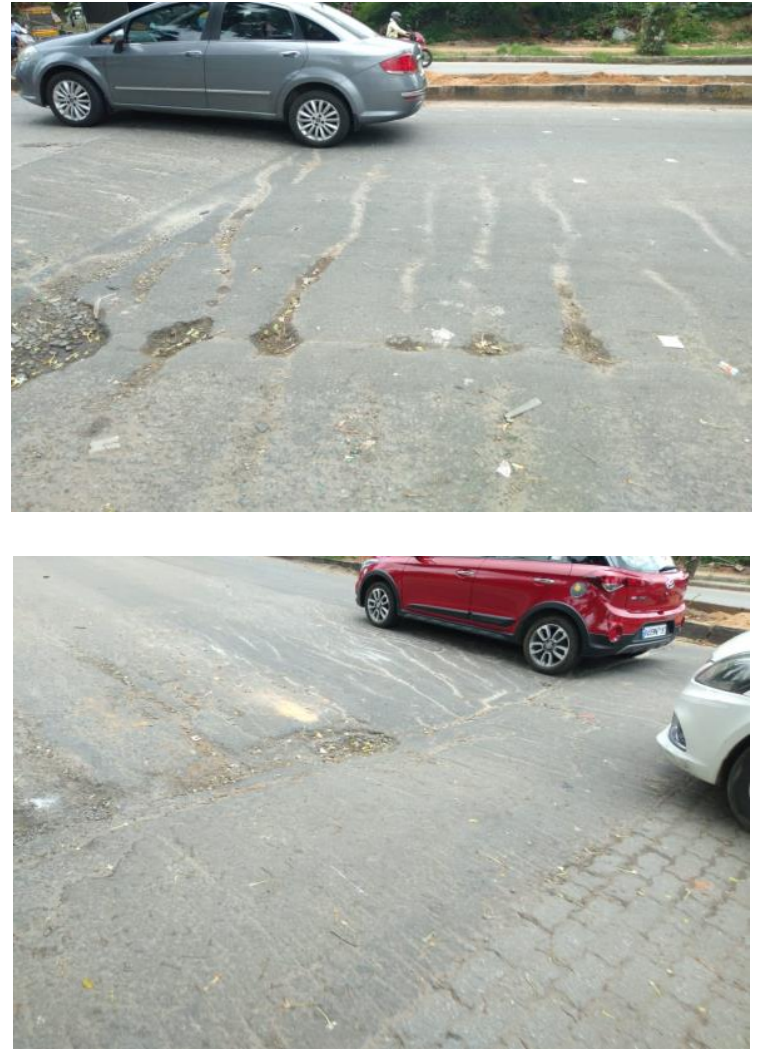

Fig. 5. Road condition in corridor

\section{Data Analysis and Results}

The speed profile data collected in the study corridors were investigated for both free flow and peak flow conditions in each segment. The moving average (3MA) technique is used to smoothen the speed profile, speed data by removing the clamors in data. In the corridor the geometry, demand and traffic flow attributes were not uniform. So, the study corridor was partitioned into a few segments for the investigation. The corridor was partitioned into eight segments.

Using motorised two-wheeler the speed profile data on corridor were collected and analysed with a moving average (3MA) method to obtain the mean speed of the motorised twowheeler. The mean speed is calculated both peak flow and free flow for corridor and was plotted with their respective distance to obtain their quality of service on the facility.

The corridor as a distance of $2.96 \mathrm{~km}$ was divided into eight segments, the segment 1 as a distance of $190 \mathrm{~m}$, the segment 2 as a distance of $1750 \mathrm{~m}$, the segment 3 as a distance of $450 \mathrm{~m}$, the segment 4 as a distance of $560 \mathrm{~m}$, the segment 5 as a distance of $250 \mathrm{~m}$, the segment 6 as a distance of $420 \mathrm{~m}$, the segment 7 as a distance of $570 \mathrm{~m}$ and, the segment 8 as a distance of $1710 \mathrm{~m}$. The free-flow speed in corridor was shown graphically concerning the distance, from segment 1 to segment 4 were shown in Fig. 6(a) and, form segment 5 to segment 8 was shown in Fig. 6(b) The peak flow speed in corridor was shown graphically concerning the distance, from segment 1 to segment 4 was shown in Fig. 6(c) and from segment 5 to segment 8 was shown in Fig. 6(d). The free-flow conditions mean speed and peak flow conditions mean speed were plotted concerning their distance of travel along the stretch of the corridor.

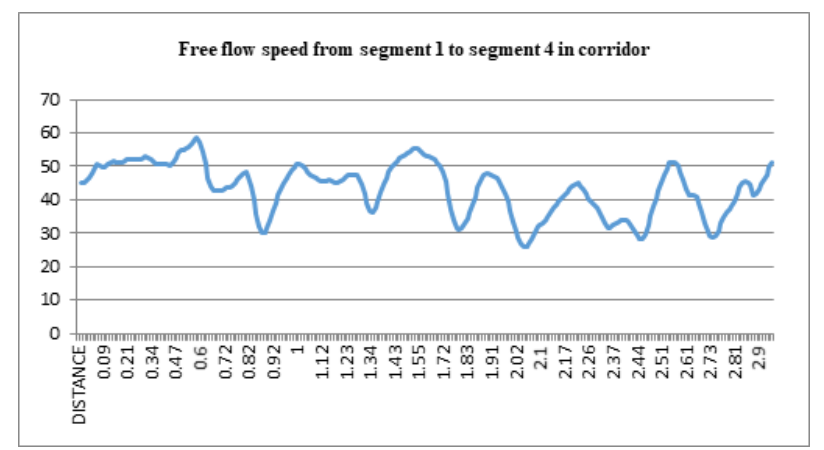

Fig. 6(a). Free-flow speed from segment 1 to segment 4 in corridor

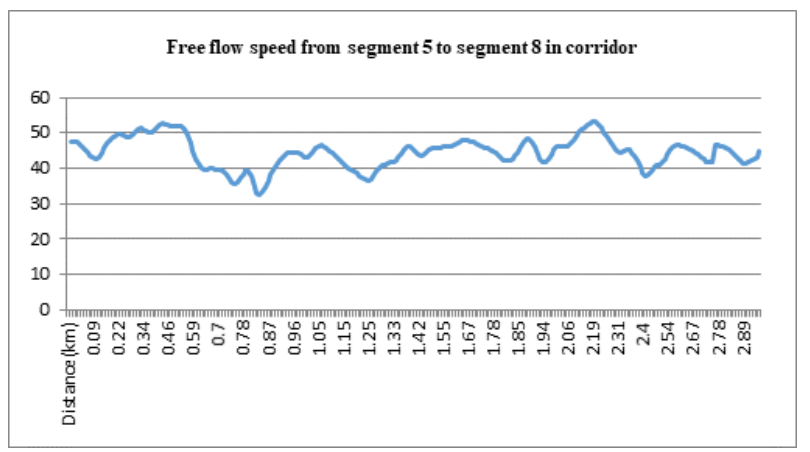

Fig. 6(b). Free-flow speed from segment 5 to segment 8 in corridor

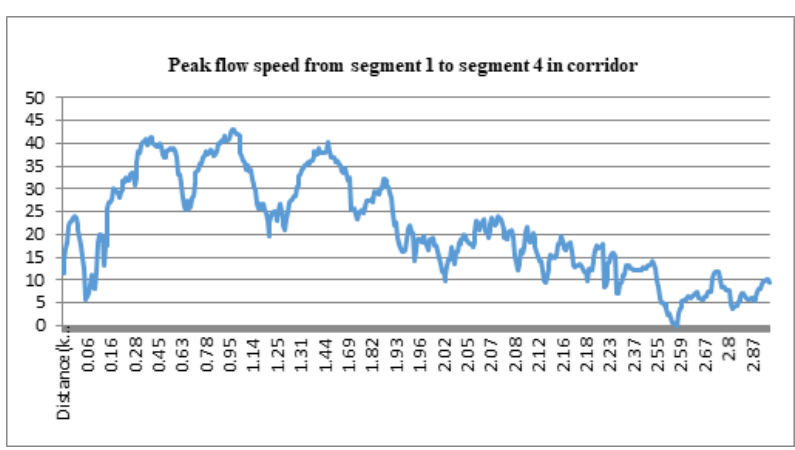

Fig. 6(c). Peak flow speed from segment 1 to segment 4 in corridor

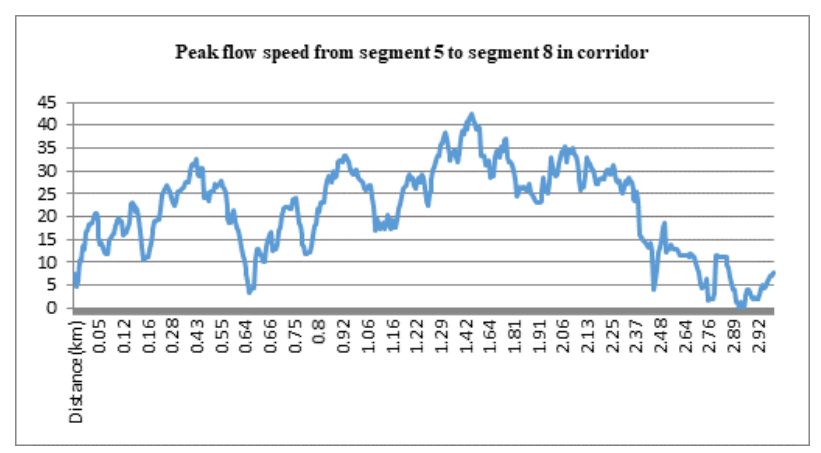

Fig. 6(d). Peak flow speed from segment 5 to segment 8 in corridor

From the graphs we can compare the variation in speed 
profile for every segment in the study corridor. The free flow and peak flow speed in segment 1 is $44 \mathrm{~km} / \mathrm{hr} \& 19 \mathrm{~km} / \mathrm{hr}$, for segment 2 is $44 \mathrm{~km} / \mathrm{hr} \& 34 \mathrm{~km} / \mathrm{hr}$, for segment 3 is $52 \mathrm{~km} / \mathrm{hr}$ \& $22 \mathrm{~km} / \mathrm{hr}$, for segment 4 is $44 \mathrm{~km} / \mathrm{hr} \& 25 \mathrm{~km} / \mathrm{hr}$, for segment 5 is $46 \mathrm{~km} / \mathrm{hr} \& 20 \mathrm{~km} / \mathrm{hr}$, for segment 6 is $50 \mathrm{~km} / \mathrm{hr} \& 26$ $\mathrm{km} / \mathrm{hr}$, for segment 7 is $42 \mathrm{~km} / \mathrm{hr} \& 22 \mathrm{~km} / \mathrm{hr}$ and, for segment 8 is $39 \mathrm{~km} / \mathrm{hr} \& 30 \mathrm{~km} / \mathrm{hr}$. The variation in speed profile between free flow and peak flow is due to traffic congestion, geometric characteristics, and vehicle characteristics on the road this caused for reduction in speed over the segments in corridor.

\section{A. Speed indices}

In heterogeneous traffic conditions, the driver perception of quality of travel over the study corridor in all the segments is specified by the unconventional parameters which will exactly identify and narrate the speed variation characters of travel over the facility. The velocity noise (VN), the coefficient of variation of speed (CV), acceleration noise (AN) and, the mean velocity gradient (MVG) are the speed indices considered for the study and this were calculated for all the segments in study corridor considering both peak flow condition and free flow condition, the results for free flow are shown in Table 2, and the results for peak flow conditions are shown in Table 3.

Table 2

Free-flow speed indices results of segments

\begin{tabular}{|c|c|c|c|c|}
\hline Segment & VN & CV & AN & MVG \\
\hline $\mathbf{1}$ & 2.8 & $\mathbf{7}$ & 1.3 & 3.1 \\
\hline $\mathbf{2}$ & 7.6 & $\mathbf{1 8}$ & 2.2 & 5.3 \\
\hline $\mathbf{3}$ & 6.8 & $\mathbf{1 4}$ & 3.0 & 5.5 \\
\hline $\mathbf{4}$ & 7.7 & $\mathbf{1 7}$ & 2.4 & 5.6 \\
\hline $\mathbf{5}$ & 3.6 & $\mathbf{8}$ & 1.3 & 2.9 \\
\hline $\mathbf{6}$ & 4.1 & $\mathbf{9}$ & 1.1 & 2.2 \\
\hline $\mathbf{7}$ & 6.7 & $\mathbf{1 6}$ & 2.0 & 4.9 \\
\hline $\mathbf{8}$ & 9.3 & $\mathbf{2 4}$ & 3.8 & 9.7 \\
\hline
\end{tabular}

Table 3

Peak flow speed indices results of segments

\begin{tabular}{|c|c|c|c|c|}
\hline Segment & VN & CV & AN & MVG \\
\hline $\mathbf{1}$ & 9.8 & $\mathbf{5 2}$ & 3.4 & 18.1 \\
\hline $\mathbf{2}$ & 8.3 & $\mathbf{2 4}$ & 3.1 & 9.2 \\
\hline $\mathbf{3}$ & 11.5 & $\mathbf{5 7}$ & 1.9 & 10.6 \\
\hline $\mathbf{4}$ & 8.6 & $\mathbf{3 5}$ & 1.8 & 7.3 \\
\hline $\mathbf{5}$ & 6.3 & $\mathbf{3 3}$ & 2.0 & 10.3 \\
\hline $\mathbf{6}$ & 6.4 & $\mathbf{2 6}$ & 1.7 & 6.7 \\
\hline $\mathbf{7}$ & 10.7 & $\mathbf{4 9}$ & 2.3 & 10.7 \\
\hline $\mathbf{8}$ & 9.8 & $\mathbf{3 3}$ & 3.7 & 12.2 \\
\hline
\end{tabular}

The speed and standard deviation of speed of automobile in computing trips the speed profile fluctuations can be observed effectively using the most suitable parameter CV. Increase in flow up to half its capacity cause increase in the $\mathrm{CV}$, increase in flow higher than its half capacity causes to starts reduction in $\mathrm{CV}$ at a particular limit (Drisya Manghat, Karuppanagounder Krishnamurthy, 2019) then the following behavior condition of driver starts losing the freedom to manoeuvr, this is due to the random behavior of traffic in the lower flow condition, hence $\mathrm{CV}$ will starts to obtain decreasing tend. The $\mathrm{CV}$ as its effect on each of the segment in the corridor, when higher the changes in the standard deviation of speed than there will be higher CV value and it is in the percentage value. In roadway the variation in speed of the automobile over the segment in study corridor is expressed as standard deviation of speed, this will reflects the level of efforts needed to place by driver to sustain speed profile over the segment by indirectly. The AN is known as the standard deviation of acceleration along with the segments in corridors. MVG is the ratio of acceleration noise to the mean speed in the segment.

From the speed indices results both from free-flow and peak flow we can decide the quality of travel over the particular segment in the corridor.

\section{Conclusion}

The assessable quality of four-lane two-way divided corridors as proposed with a new methodology in this study by considering the variation characteristics of speed in the urban corridor. The GPS based mobile application is employed in vehicle to record the speed profile of motorised two-wheeler in the study corridor. The various types of automobile modes in the urban streets represents a distinct speed profile patterns with a unique Automobile level of service (ALOS) experience perceived by the individual mode users under the most identical traffic flow conditions. Speed indices were calculated from the collected free flow and peak flow speed profile. CV is considered as the measure of effectiveness, it is used to validate the quality performance of level of service on urban corridor.

As a future studies, this study is done for Bangalore in Karnataka, India. A comparative study can be completed in different urban areas of India. The India consists of huge assorted varieties within their driving characteristics and its people livings. The Motorised two-wheelers (MTW) were considered for this research, the MTW are used for data collection purposes. In heterogeneous traffic, many modes of travel need to be quantified for defining the quality perceived by each mode of travel.

\section{References}

[1] D. Manghat, and K. Krishnamurthy, "Performance evaluation of urban corridors using the speed profile data of automobiles," Travel Behaviour and Society, vol. 18, pp. 58-67, January 2020.

[2] M. V. I. R. Anjaneyulu, and B. N. Nagaraj, "Modelling congestion on urban roads using speed profile data," J. Indian Roads Congress, 2009.

[3] Y. S. Babu, and S. B. Pattnaik, "Acceleration noise and level of service of urban roads-a case study," J. Adv. Transp., vol. 31, pp. 325-342, 1995.

[4] A. Flannery, N. Rouphail, and D. Reinke, "Analysis and modeling of automobiles users' perceptions of quality of service on urban streets," Transp. Res. Rec., vol. 2071, no. 1, pp. 26-34, 2008.

[5] Indian Road Congress. (IRC). "Geometric Design Standards for Urban Roads in Plains", IRC 86, New Delhi, 1986.

[6] National Cooperative Highway Research Program (NCHRP) 616. "Multimodal level of service analysis for urban roads," Transportation Research Board, Washington D C, 2008.

[7] Transportation Research Board (TRB): Highway Capacity Manual, Transportation Research Board of the National Academies, Washington, DC, 2000.

[8] Transportation Research Board (TRB): Highway Capacity Manual, Transportation Research Board of the National Academies, Washington, DC, 2010. 
[9] Transportation Research Board (TRB): Highway Capacity Manual, Transportation Research Board of the National Academies, Washington, DC, 2016.

[10] Indian Highway Capacity Manual (Indo-HCM): Central Road Research Institute, New Delhi, 2017.

[11] P. K. Bhuyan, and K. V. K. Rao, "Defining level of service criteria of urban streets in Indian context," Eur. Transp. Transporti. Europei., vol. 49, pp. 38-52, 2011. 